\title{
La protesta popular en Cartagena 1900-1920
}

\author{
María Bernarda Lorduy Flórez
}

Presentado: abril de 2011

Aprobado: octubre de 2011

\section{Resumen:}

Las siguientes páginas analizan las protestas populares en Cartagena a comienzos del siglo XX, específicamente el levantamiento popular de 1910 contra el arzobispo de la ciudad Pedro Adán Brioschi, y la huelga de los trabajadores del puerto en 1918. El propósito es el de establecer las debidas diferencias entre la protesta social de corte tradicional y la protesta social moderna expresada en su mejor forma por los trabajadores.

\section{Palabras claves:}

Protesta social, liberalismo, Cartagena, trabajadores.

\section{Abstract:}

The following pages discuss the popular protests in Cartagena in the early twentieth century, specifically the 1910 popular uprising against the archbishop of the city Brioschi Pedro Adan, and the strike by port workers in 1918. The purpose is to establish the necessary differences between the social protest of traditional and modern social protest expressed in his best form for the workers.

Key words:

Social protest, liberalism, Cartagena workers. 


\section{Presentación}

$\mathrm{L}$ os movimientos de protestas suscitados en el penúltimo tránsito finisecular centuria se constituyeron en asonadas esporádicas y poco organizadas, pero articuladas a una incipiente red de pertenencia e identidades. Por lo general cohesionaron a la sociedad baja y media en momentos en que esta veía reducidos sus derechos frente a las instituciones del orden legitimador. La protesta de 1910 estuvo más asociada a las estructuras normativas y culturales de las relaciones iglesia, Estado y sociedad. Pero a diferencia de éstos, la forma de protesta social representada, en la huelga de braceros de 1918, se constituyó progresivamente en un levantamiento estable, organizado y con claros objetivos e ideologías visibles que luchaban por conservar viejas costumbres y nuevos derechos, colocando un precedente político que asociaba a los trabajadores, a un fin común mucho mas elaborado y cercano a sus expectativas como clase. Esta protesta tuvo amplias repercusiones en el ámbito local y nacional, y también condicionó en años posteriores, una singular "aceptación" de la actividad huelguística.

Las protestas como formas consciente de reclamación no fueron desarrolladas por individuos desvinculados unos de otros; la multitud que ejercía presión ante las autoridades legitimadoras del orden social era homogénea en cuanto que su presión estaba condicionada por marcos culturales que determinan su conducta y afiliaciones sociales, y desde esos marcos leían el mundo y los cambios sociales que se estaban suscitando a sus alrededores. En Cartagena la multitud aparece bajo diversos rostros que se conjugan durante la protesta: panaderos, zapateros, maestros, juristas, albañiles, sastres, mecánicos, artistas, holgazanes y demás despreocupados, ocuparon las calles de la ciudad, se valieron de la misma institucionalidad y ejercieron presión, acción y "devoción" en sus reclamaciones.

En este artículo entendemos por movimientos de protesta los levantamientos limitados en su difusión espacial, a menudo de carácter local, regional o nacional que representan un grupo de presión que no desarrolla una ideología muy elaborada. No obstante, la puntualidad de sus acciones permite soluciones a corto plazo. Se diferencia de los movimientos sociales porque estos representan acciones colectivas más o menos permanentes orientadas a enfrentar injusticias, desigualdades o exclusiones, poseen una duración mayor y están más integrados que las turbas, las masas y las multitudes, pero menos organizados que los clubes políticos y otras asociaciones; en esencia constituyen la determinación tajante de cambio, y la fuerte convicción de quienes oran por ese cambio. Los movimientos de protesta, por su parte, tienen como finalidad recuperar o mantener privilegios sin atacar los cimientos del orden social ${ }^{1}$.

\footnotetext{
${ }^{1}$ Mauricio Archila, "Vida y pasión de los movimientos sociales en Colombia", en Movimientos sociales, Estado y democracia en Colombia, Bogotá, Universidad Nacional, 2001, p. 18
} 
Este artículo es un intento de explorar el universo social, en el cual la multitud cartagenera hizo visible su inconformidad, a través de la protesta popular, en cuanto las estructuras cotidianas de orden social, económico, político y cultural sufrieron alteraciones. Para este fin es necesario un dialogo entre académicos y actores que haga explicitó un nuevo proceso investigativo en el que unos y otros pongamos en circulación los conocimientos y las experiencias, con este dialogo evitaremos el apresuramiento al exaltar lo que no ha nacido o peor aún, enterrar lo que todavía esta vivo ${ }^{2}$. Esto exige por tanto, mirar mas allá de los modelos eurocéntricos y del modelo desarrollista, fijar horizontes llenos de expectativas y singular esperanza a nuestros propios procesos históricos a merced de una buena reconstrucción del pasado de aquellos que fueron ignorados y recelosamente documentado ${ }^{3}$.

El artículo consta de tres partes; la primera, explora de manera general la consolidación de la historia desde abajo en la historiografía mundial. De igual manera analiza las características e hitos más sobresalientes de la historia de las movilizaciones populares, sus limitantes y sus retos para el caso colombiano. La segunda y tercera parte, explican la dinámica de los movimientos populares que tuvieron como epicentro la ciudad de Cartagena. En primera instancia, el levantamiento popular contra el arzobispo Pedro Adam Brioschi, en diciembre de 1910 ocurrido por la venta de unos bienes de la diócesis a extranjeros norteamericanos, originando reacciones diversas entre la multitud y las autoridades civiles, y recreando sentimientos antiimperialista, anticlerical y regionalista. En segundo término la huelga de braceros del puerto de Cartagena en 1918, originada como fruto de dinámicas externas (como la huelga de trabajadores en Barranquilla en 1893, y posteriormente en 1918), como por factores sociales, económicos y políticos de la ciudad, los que condicionaron la capacidad de negociación de los trabajadores con los empresarios, al tiempo que construían mecanismos mucho más elaborados de participación y de acción popular (los sindicatos).

${ }^{2}$ M. Archila, "Vida y pasión de los movimientos sociales en Colombia", pp. 28-33

${ }^{3}$ Ahora bien, a diferencia de la copiosa historiografía de los movimientos precursores de la emancipación hispanoamericana, los movimientos que le preceden están menos documentados, lo que hoy advierte un campo de investigación en construcción y contaste evaluación, cuyas fuentes y demás materiales son en gran mediada escasos o inexistentes. la historiografía sobre los movimientos de emancipación, es hoy muy rica. en ella la multitud ha sido estudiada y valorada dentro del juego de los acontecimientos. ya no es reducida como "carne de cañón" en las contiendas de emancipación -la multitud, dentro de las revoluciones fueron garantes de victoria, verdaderos directores, jueces, impulsores y mediadores de un proceso, que nos trajo la libertad. fueron piezas claves para desestabilizar el régimen español en América. si bien nunca se busco una independencia definitiva de España, se dieron brotes de malestar contra las disposiciones del régimen, que afectaban el normal desarrollo de la economía, la política y la sociedad en general. por ello son protestas de corte negociador, amenazan el régimen pero no buscan derrocarlo. sin embargo, en sus pliegues hay ciertas pautas que condujeron aun cambio total a mediano plazo. en este punto nuestro estudio tratara de establecer los cambios y continuidades, dados entre los levantamientos populares de principios de siglo XX, específicamente el de 1910, y los de corte sindical, cuya finalidad y compresión presentan variables interesantes. ver: Alain Touraine, Las clases sociales en América Latina, México, eds. Siglo XXI, 1973. 


\section{Consideraciones generales acerca de la protesta social}

Durante los últimos 40 años la historiografía británica ha venido impulsando la llamada historia social ${ }^{4}$, iniciada en Francia con la conformación del movimiento de Annales y luego extendida por casi toda Europa Occidental. La historiografia social inglesa ha contribuido notablemente al mundo académico, proporcionando una gama de elementos conceptuales para el estudio de los movimientos sociales y la intervención de las masas en procesos históricos destacando tres aspectos: el universo mental, el social y el político. Estos elementos claves de la vida humana fueron durante largo tiempo ignorados o rezagados dentro de la historia tradicional, cuyo único objetivo fue ambientar las actitudes y aspiraciones de los notables, al servicio de los poderes legítimos, que rechazaba la teoría y tenía a la narrativa como hilo conductor.

Para George Rudè la multitud es lo que lo sociólogos denominan un grupo de "contacto directo" o "cara a cara", multifacético, vivo e irreverente; no es un tipo de fenómeno colectivo tal como un clan, una casta o un partido político, una comunidad rural, una clase social o otra colectividad demasiado grande para ser reunida ${ }^{5}$. Mujeres y hombres de carne y hueso que al salir de su invisibilidad rompieron viejas creencias y reduccionismos, despolarizando la historia de los buenos y los malos; buscando analizar las estructuras sociales en ayuda a explorar el acontecer político, económico y cultural. En ayuda a autopercibirse, y elaborar una nueva ruta de su historia que traspase las ideas del otro, y entren en juego sus ideas, sentimientos y expectativas mas inmediatas.

Las formas características de la protesta son por lo general la tradición anónima, el contrateatro y la acción rápida y directa donde la multitud opera como es sui generis, con sus propios objetivos y dentro de una compleja y delicada polaridad de fuerzas en su propio contexto. La ciudad, la calle, la plaza, son los escenarios sobre los cuales la protesta despliega sus dramatizaciones. El movimiento se convierte en un espectáculo que rompe la rutina diaria, invade las conciencias y el imaginario individual. La acción explora tales condiciones, es un canal a través del cual se trasmite el mensaje, el sobresalto alterado como medio de forzar la atención pública, se sirve de los medios de masas y hace de ellos un amplificador y una arma capaz de extender el miedo por contagio. Su fin no es producir un cambio radical, informa al poder, pero no lo amenaza de manera inmediata o contundente, pone en escena una contestación controlada que ha renunciado a su estado "salvaje"; que se apoya en viejas tradiciones "paternalistas" para impulsar sus objetivos ${ }^{6}$.

\footnotetext{
${ }^{4}$ E. P. Thompson, Costumbres en común, Barcelona, ed. Crítica, 1995, pp. 216-217. Raphael Samuel (ed.), Historia popular y teoría socialista, Barcelona, ed. Critica, 1979; E. P. Thompson, Tradición, revuelta y conciencia de clase, Barcelona, ed. Critica, 1974; Julián Casanova, La historia social y los historiadores, Barcelona, ed. Critica, 1991; Eric Hobsbawm y George Rudè, Revolución industrial y revuelta agraria. El Capitán Swing, Madrid, eds. Siglo XXI, 1978; Mario Aguilera y Renán Vega, Ideal democrático y revuelta popular, Bogotá, Universidad Nacional, 1998.

5 George Rudè, la multitud en la historia (1730-1848), Madrid, eds. Siglo XXI, 1984, pp. 8-9.

${ }^{6}$ George Balandier, El poder en escenas, Madrid, ed. Paidós, 1997, pp. 27-32. Albert Soboul, La Revolución Francesa, Barcelona, ed. Critica, 1978; E. P. Thompson, Tradición, revuelta y conciencia de clase, pp. 29-37
} 
El motín constituye un fenómeno urbano casi universal que desempeña una función política y está siempre condenado a frustrarse; pero fija límites a los dominadores. A través de sus acciones se demuestra que la multitud es capaz de reaccionar voluntariamente-no se pasa por alto la influencia de algún líder o ideología- ante determinada situación que considere injusta o desproporcionada a sus intereses. No transforma el sistema dado que no es su objetivo, pero muy posiblemente toca las raíces más sensibles de los problemas que conciernen a la sociedad ${ }^{7}$. El objetivo queda definido por sus acciones, que se hacen evidentes en las frases, oraciones o reacciones que siguen los movimientos desde el mismo punto de efervescencia. La eficacia de una insurrección depende de tres factores: con qué facilidad pueden ser movidos los pobres, cuan vulnerables sean para estos los centros de autoridad y cuán fácil pueden ser liquidados.

Muchas veces la voluntad de castigo, presente durante la protesta corresponde a una concepción confusa de justicia popular. El pueblo no se considera culpable ante tales acciones; al contrario, está convencido de que juzga y castiga oportunamente. La reacción popular, va en este terreno desde un mero reflejo de defensa, la tasación, hasta la voluntad de represión mediante el saqueo y el incendio a sitios o puntos neurálgicos de la ciudad. Esto hace parte de su ofensiva, y no se le atribuyen fines vandálicos o desmedidos, como muchos intelectuales consideraban a este tipo de acción. Las masas recrean en sus movilizaciones las afinidades heredadas, usurpadas o adquiridas de todo un proceso político, económico y social, que condiciona su protesta, y extiende su capacidad de reacción, y negociación frente al grupo al que hacen la reclamación ${ }^{8}$.

La revuelta es la forma característica y recurrente de la protesta que en ocasiones se transforma en rebelión o revolución. El estudio de este tipo de movimiento por lo general ha padecido de dos enfoques estereotipados. El primero más liberal, humano y democrático insiste en leer la historia hacia atrás y adscribir tales actividades sin mayor investigación a la clase obrera' ${ }^{9}$; el otro estereotipo más de moda entre los escritores conservadores, consiste en aplicar la etiqueta de turba o populacho, sin discriminación a todos los participantes de los disturbios populares, "una banda de crueles", "rufianes", "ladrones", "tipos disolutos y levantiscos", todos estos términos presentaban a la muchedumbre como descarnada abstracción y no como un conjunto de mujeres y hombres de carne y hueso, de servicio y oficio. En resumen, ambos enfoques reducen a los

${ }^{7}$ Rudè estudió el conjunto de creencias prepolíticas de la multitud tales como la antipatía hacia la innovación capitalista, que se expresa como un rechazo de las sociedades de pequeños productores a las manifestaciones significativas del capitalismo, los monopolios, la usura, etc.; el gobierno como padre y protector que vela por el bien colectivo de los súbditos, y el instinto nivelador, el deseo de los pobres de obtener cierto grado de justicia social.

${ }^{8}$ Ver Eric Hobsbawm, "Rebeldes y revolucionarios" en Revolucionarios, Barcelona, ed. Crítica, 2000, p. 283. A. Soboul, La Revolución Francesa; Zogorin Pérez, Revueltas y revoluciones en la edad moderna, Madrid, ed. Cátedra, 1985.

${ }^{9}$ Lo anterior no significa que se desconozca la importancia de la categoría clase social. Para esta investigación lo que se critica es la reducción que de ella se hace a la esfera productiva, lo que a todas luces le hace incompleta para explicar la complejidad del conflicto social, al igual la objeción se centra en tomar las acciones obreras como margen de comparación para el estudio de otros movimientos cuyo contexto, actores, móviles y finalidad no va en concordancia con su situación histórica. 
participantes de los movimientos populares a lo que Carlyle llamó una "fórmula lógica muerta" que no comporta mayor relevancia histórica.

En conclusión la protesta se ha convertido en las sociedades de libertades en un medio institucionalizado o casi, codificado y ritualizado de mostrar la oposición a determinadas decisiones de los gobernantes, autoridad civil o eclesiástica o de poner de relieve los efectos inaceptables de una situación. La tarea de identificar los rastros y con ellos los rostros de la multitud esta rodeada de obstáculos y problemas; la idea inmediata es construir analítica, estructural e ideológicamente el material histórico obtenido, conjugando actores y realidad historia, pero bajo limitantes ineludibles ${ }^{10}$.

\section{Acción y devoción: la protesta de 1910}

En Colombia la segunda mitad del siglo XIX se caracterizó por la inestabilidad política, pues seis guerras civiles nacionales y unos cuarentas levantamientos y pronunciamientos locales dan buena cuenta de los obstáculos interpuestos para el desarrollo del estado-nación y de la fragilidad de los regímenes políticos. Desde 1850 hasta 1885 hubo un predominio liberal con breves ausencias en 1854 y 1861. El régimen liberal sucumbió en 1885 y comienza un dominio conservador hasta $1930^{11}$.

La república conservadora se caracterizó por continuos enfrentamientos y álgidos debates entre las colectividades políticas en torno al tema religioso, lo que era síntoma del malestar político a raíz del reordenamiento del espacio político que implicó la exclusión de los contrarios políticos y la persecución de lo todo lo que pudiera ser visto como protesta social, o como acciones contrarias a las nuevas orientaciones en torno a la familia, la educación, el arte, la economía, el tratamiento de la delincuencia, la pobreza y la sociabilidad, entre otros . Es en este periodo cuando se consolida el poder simbólico y cultural del clero, y la intolerancia política respecto al pensamiento de las luces y del socialismo $^{12}$.

Así mismo se hizo evidente el desfase entre la industrialización, y la ausencia de modernidad social, cultural y política. Uno de los principales temores del movimiento regenerador, lo suscitaba el recuerdo de las movilizaciones de los años anteriores. Por esos mismos miedos, los regeneradores pretendían instaurar un orden social como forma de evitar el desarrollo de peligrosas ideologías socialistas, y de impedir el paso traumático al

${ }^{10}$ G. Rudé, La multitud en la historia, pp. 19-22. Eric Hobsbawm, Rebeldes primitivos, Barcelona, ed. Ariel, 1974; Jim Sharpe, "Historia desde abajo", en Peter Burke (ed.), Formas de hacer historia, Madrid, Alianza ed., 1996, pp. 38-58; E. Hobsbawm y G. Rudè, Revolución industrial y revuelta agraria. El Capitán Swing.

${ }^{11}$ Marco Palacios, El café en Colombia, Bogotá, El Áncora eds., 1979; Mario Aguilera, Insurgencia urbana en Bogotá, Bogotá, Colcultura, 1997, p. 79; Medófilo Medina, La protesta urbana en Colombia en el siglo XX, Bogotá, eds. Aurora, 1984; Paul Oquist, Violencia, conflictos y política en Colombia, Bogotá, Banco Popular, 1978.

${ }^{12}$ P. Oquist, Violencia, conflictos y politica en Colombia. 
capitalismo $^{13}$. Un orden que permitiera unificar la nación desde arriba, que no buscaba ampliar la participación política de las masas, sino, restringirla severamente. Este proyecto centralizador reaccionario tuvo mayor viabilidad política después de $1904^{14}$.

De otro lado, aunque la institución eclesiástica era poderosa e influyente a nivel nacional, su debilidad política era evidente en la región costeña. Esto puede observarse a través de las confrontaciones que sucedieron entre la población y la jerarquía católica y entre las autoridades civiles y eclesiásticas durante los primeros años del siglo $\mathrm{XX}^{15}$. Un ejemplo de esto se evidenció durante los días 28 y 30 de mayo de 1905 en Cartagena, cuando ante la petición del Arzobispo a la Asamblea Departamental para que se diera una parte del local del antiguo Convento de Monjas de Santa Teresa a las Hermanas de la Caridad, se opusieron algunos miembros de dicha asamblea, como el Barranquillero Francisco Pasos, alegando que el edificio podía servir como cuartel; los vociferadores en la sección de la asamblea llegaron a gritar, entre otras cosas: "ustedes quieren regalar lo que no les pertenece, ese es un bien del pueblo ese bien es nuestro, y nosotros los defenderemos, no queremos regalarlo..."

Para la iglesia cartagenera estos incidentes demostraban que los liberales de la ciudad manipulaban al pueblo con actos demagógicos. Sin embargo, la misma institución eclesiástica era consciente que en esto tenia mucho que ver la fragilidad y relativa aceptación que existía en la región de las normas y símbolos de representatividad religiosas. De esos pueden dar cuenta los actos de sacrilegios que, según las autoridades de la iglesia se cometieron durante la guerra de los Mil Días en poblaciones como Piojo, Calamar, Arenal, Lorica y Corozal. El arzobispo de Cartagena relato así los hechos acaecidos en Corozal: "El bautismero había [sido] destinado para depósito de pólvora, cascarones de cápsulas y bayonetas; una de las naves fue convertidas en pesebrera y la otra en matanza de ganado... el agua bendita de las pilas fue reemplazada por orines, las bancas son escenario de actos impuros... “17.

Esta mirada a vuelo de pájaro sobre estos enfrentamientos y situaciones "enojosas" para la iglesia, permitieron contextualizar la protesta popular en Cartagena de 1910, los sucesos del 10 de ese mes una vez más puso en evidencia la frágil relación existente entre la iglesia y la sociedad. Ese día se presentó un levantamiento popular contra el arzobispo Pedro Adán

\footnotetext{
13 Jorge O. Melo, "La república conservadora", en Colombia hoy, Bogotá, Siglo XXI, 1981; Miguel A. Urrego, "La regeneración (1879-1898)", en Gran enciclopedia de Colombia, Bogotá, Círculo de Lectores, 1991, pp. 421-450.

${ }^{14}$ M. Palacios, El café en Colombia, pp. 78-80. Gustavo Bell (ed.), El Caribe colombiano, Barranquilla, eds. Uninorte, 1986; Adolfo Meisel (ed.). Historia económica y social del Caribe colombiano, Barranquilla, ed. Uninorte, 1994.

${ }^{15}$ Eduardo Posada, "Iglesia y política en la Costa Atlántica", en Huellas No 19, Barranquilla, Universidad del Norte, 1987.

${ }^{16}$ Archivo Eclesiástico de Cartagena [AEC], Pastoral del año 1905 "Los escándalos del 28 y 30 de mayo" en El Vocero $\mathrm{N}^{\circ}$ 8. Pastoral, doc. of. $\mathrm{N}^{\circ} 24,1901$.

17 AEC, Pastorales, doc. of. № 53, 1901.
}

El Taller de la Historia, vol. III, $N^{\circ}$ 3, 2011, págs. 85-108. Issn: 1657-3633

Programa de Historia, Facultad de Ciencias Humanas, Universidad de Cartagena de Indias, Colombia 
Brioschi. El hecho desencadenante de este suceso fue la venta que pretendía el obispo, de algunas propiedades de la iglesia (el edificio de San Pedro Claver, las accesorias construidas detrás del seminario, la casa de la calle de la Factoría, donde estaba el colegio de San Pedro Apóstol, y el Palacio Arzobispal), a una organización Norteamericana ${ }^{18}$.

La venta de estas propiedades desató la protesta popular, la que puso de presenta importantes aspectos de la cultura política común y corriente de la época que apenas comenzamos a explorar: el antiimperialismo, el anticlericalismo y ciertas tradiciones y novedades en la misma ligados a lo que se concibe como el equilibrio social, el buen gobierno y las relaciones región-estado central. En efecto, la protesta bajo la concepción de una lección de la soberanía nacional, ya latente desde la separación de Panamá en 1903; también puso a la orden del día viejos temores, rencores y anhelos dentro del conjunto de la sociedad en temas determinantes. De alguna forma cuestionaba las directrices del régimen conservador y clerical, que se basaba en la exclusión de los contrarios políticos y la intolerancia con las ideas que rivalizaban con al institucionalidad. En el mismo sentido, el motín puso de manifiesto el resentimiento de la diligencia regional hacia las autoridades centrales, y las inconformidades que las políticas nacionales generaban en la Costa Caribe.

\section{La acción social}

La iglesia como institución, más que como comunidad de creyentes, actúa dentro de los marcos institucionales del Estado. Es frente a este que logra afirmar su legitimidad; así se asegura su supervivencia y su influencia en la vida de los creyentes. Y el Estado por su parte, garantiza el papel que a aquella le corresponda dentro de la sociedad. Entonces, para poder comprender su funcionamiento hay que situarse dentro de este diálogo IglesiaEstado.

La iglesia durante el régimen radical había perdido su función hegemónica en el campo ideológico desde que el liberalismo se consolidó en Colombia. Así mismo, el vínculo Iglesia-Masas populares decayó lentamente a medida que cambiaron las condiciones socioeconómicas y se establecieron nuevas relaciones en las que prioriza lo material. Así los lazos de unión y comunicación varían de acuerdo a las estructuras, y conveniencias de la nueva realidad. Para contrarrestar esta situación durante la Regeneración y la Hegemonía Conservadora el clero pone en marcha una campaña que tenía por objeto controlar a los fieles con la caridad y la beneficencia. A cambio de ello estaban obligados a cumplir con sus deberes cristianos, exigiéndoles la moralidad y el cumplimiento de los designios de la iglesia. La difusión de sociedades e institutos de caridad tiene un sentido político de orientación al mantenimiento de sus adeptos, recreando las tradiciones, valores y dogmas católicos, frente a lo que se percibe como la introducción cada vez más notoria del

${ }^{18}$ AEC, Pastoral, doc. of. $N^{\circ}$ 94, 1910. Archivo Histórica de Cartagena (Colombia) [AHC], "Motines en Cartagena", en El Caribe, Cartagena, diciembre 13 de 1910. El Liberal, Cartagena, diciembre 17 de 1910. 
protestantismo y de la mentalidad liberal desde las logias masónicas ${ }^{19}$. Estas estructuras de sociabilidad lograron identificar al pueblo con la iglesia y permitieron que ésta ejerciera un control más eficaz sobre los espacios de influencia económicos y políticos ${ }^{20}$.

Durante la segunda mitad del siglo XIX se habían organizado en diferentes regiones del país asociaciones de raíz popular que tenían como finalidad el auxilio mutuo de sus afiliados. Algunas derivaron de su carácter exclusivamente religioso hacia sociedades civiles de mutuo auxilio, de ahorro, de socorro para la vejez y muerte, seguro contra accidentes, de trabajo y enfermedad. En este tipo de sociedad se mezcló por lo menos en teoría, el ingrediente teocrático y el ideológico-socialista. ${ }^{21}$ Según Miguel Urrutia, estas sociedades fueron el primer intento histórico de organización de los trabajadores del siglo XX para defender sus intereses comunes; en gran medida alimentadas por las experiencias y los hábitos políticos que vivió el artesanado en la segunda mitad del siglo XIX. Sin embargo, no podemos considerarlas como antecedentes directos de cuya evolución surgieron los sindicatos ${ }^{22}$.

El control del tiempo libre también fue una de las máximas preocupaciones del Estado, y encargó de esta tarea a la iglesia. La acción social católica, por ejemplo, orientó sus actividades para evitar que el pueblo proyectara en su tiempo libre preocupaciones, intereses políticos, frustraciones o vicios. ${ }^{23}$ El control sobre la prensa fue de igual manera, una temprana exigencia del clero por considerarla elemento de corrupción. La prensa podía hacer, desde el ángulo de la autoridad eclesiástica, instrumento de delincuencia contra el Estado y los particulares. Como consecuencia de esta ideología el Arzobispo de Cartagena a través de un decreto prohibió la lectura y circulación del diario El Conversador, por ser conocido bajo: "la tendencia anticatólica [a] los que redactan el mencionado diario... llevando a cabo una venganza desasociada que se propone desprestigiar al clero... la causa del espíritu de subversión y dispersión de los fieles lo constituyen los malos manejos de la información, sin más ánimo que la revolución..."24.

Se vigiló, de igual manera y con extrema cautela el derecho a reunión, prohibiéndose la agrupación de tres o más personas en lugares públicos. La restricción era síntoma de la intolerancia y la presencia de valores católicos como margen del buen ciudadano. Lo

19 Luz Gabriela Arango, Mujer industria y religión, Bogotá, Universidad Externado de ColombiaUniversidad de Antioquia, 1991; AEC, Pedro Adán Brioschi, "La masonería", en Instrucción de los prelados de la provincia eclesiástica de Cartagena. doc. of $\mathrm{N}^{\circ} 119$, Cartagena 1915. pastoral, doc. of. $\mathrm{N}^{\circ}$ 17. rerum novaron. León XII.

20 Javier Guerrero (ed.), Iglesia, movimientos y partidos. Memorias IX ${ }^{\circ}$ Congreso de Historia de Colombia, Tunja, UPTC, 1995, p. 48.

${ }^{21}$ AEC, “Conferencias episcopales de Colombia 1908-1930” pastoral. doc. of. N 17, 1916.

${ }^{22}$ Miguel Urrutia, Historia del sindicalismo en Colombia, Bogotá, ed. La Carreta, 1968; Edgar Caicedo, Historia de las luchas sindicales en Colombia, Bogotá, ed. Ceis, 1982.

${ }^{23}$ Alberto Mayor, Ética, trabajo y productividad en Antioquia, Bogotá, Tercer Mundo eds., 1986.

${ }^{24}$ AEC, "Honremos a los religiosos 1904", pastoral. doc. of. $\mathrm{N}^{\circ}$ 62, 1904. "Promulgación del jubileo extraordinario" pastoral. doc. of. $\mathrm{N}^{\circ} 69,1903$ 
interesante es que a pesar de la prohibición, las sociedades católicas respaldadas por el gobierno, el clero y la Constitución, fueron las máximas representantes del principio de sociabilidad (a diferencia de las sociedades secretas y juntas políticas). Se agruparon en dos tipos, el primero correspondía a las asociaciones conformadas por artesanos o grupos de trabajadores con el objetivo de ayudarse mutuamente; el segundo tipo de sociedades se constituyeron con un marcado énfasis en labores de culto y complemento a las actividades del clero ${ }^{25}$.

El control de la iglesia se efectuaba, así, de la esfera pública a la privada, desde el ámbito doméstico al laboral, restringiendo los espacios de participación y acción humana, condicionando los ritmos de la actividad diaria. Toda esta situación originó una crisis creciente de legitimidad de la esfera política, originando que las relaciones entre Estado, la iglesia y la sociedad tomaran matices diferentes. El incremento de la opinión pública a través de la prensa artesanal, y una mayor preocupación por parte de estos sectores en los asuntos del Estado son evidencias de la "extensión de la conciencia política"; ideas perneadas desde las capas superiores a las inferiores de la sociedad, y posibilitadas en gran medida por el mismo Estado ${ }^{26}$.

\section{Las razones del arzobispo}

Pedro Adán Brioschi nació en Tradato, cerca de Milán, Italia; había venido muy joven a Cartagena y tenía a su cargo la secretaría del obispo Monseñor Biffi, en el año del 1882. Con la muerte de éste, fue escogido por la Santa Sede como su sucesor en 1901. Por lo que aún pervive en la memoria colectiva y por algunas evidencias, este fue un personaje muy controvertido que se ganó la antipatía de los dirigentes del bipartidismo, de las autoridades y de la gente del común y corriente .Varios intelectuales han coincidido en señalar que para este periodo la Arquidiócesis de Cartagena -elevada a esta categoría pocos años después de la consagración del nuevo prelado- se encontraba en una crisis producto de la desamortización de bienes de manos muertas, lo que conduce al Arzobispo Brioschi a dotarla de propiedades y rentas que permitían la existencia decorosa de dicha institución.

Algunas de las disposiciones del Arzobispo en miras a obtener recursos económicos, causaron gran malestar entre los fieles. Apenas a un año de consagrase éste, impuso un arancel eclesiástico; aumentó los derechos correspondientes a los párrocos y fijó derechos a

\footnotetext{
${ }^{25}$ Los sacerdotes de cada parroquia eran los directores de estas instituciones bajo la dirección de otro prelado, éstos tenían como objetivo "asegurar la paz social y procurar la salvación de las almas", argumentos morales que condicionaron las relaciones iglesia-masas populares. Sin embargo, fueron estas mismas disposiciones los que paulatinamente fraccionaron las relaciones existentes creando afiliaciones ideológicas diferentes a la de la iglesia católica. AEC, "Conferencias episcopales de Colombia 19081930", pastoral, doc. of. $\mathrm{N}^{\circ}$ 17, 1916. Pastoral "honremos a los religiosos" doc. of. $\mathrm{N}^{\circ}$ 69, 1904. "Promulgación del jubileo extraordinario" doc. of. Nㅜ 62 .

${ }^{26}$ Leslie Bethell, “Economía y sociedad 1870-1930”, en Historia de América Latina, tomo VII, Barcelona, ed. Crítica-Cambridge University Press, 1991.
} 
la curia. Así mismo aumentó en un 50\% el valor de los servicios espirituales, que incluía alzas en las ceremonias y sacramentos religiosos ${ }^{27}$.

La sola posibilidad de que los liberales tomaran el poder producía escalofríos en el prelado, lo que no es de extrañar porque a pocos años de su cargo jerárquico, se produce la caída del régimen del Quinquenio de Rafael Reyes ${ }^{28}$. Esta época señala un nuevo clima político que se presentaba optimista para algunos, pero neurálgicos para otros, ya que se producen acercamientos con el Partido Liberal, vislumbrándose su posible participación en el poder. En este contexto se inscribe la preocupación por parte de Brioschi, de una posible revancha de los liberales contra la iglesia católica, porque sobrevivían algunas ideas anticlericales que podían volver a aplicarse con el liberalismo en el poder ${ }^{29}$. Por tal razón, y con el objetivo de mantener a salvo los bienes e la iglesia, el Arzobispo decidió negociar los bienes raíces mencionados, con la organización católica californiana The American organization Católica Californiana de San Francisco, la cual estaba representada por el presbítero Marco A. Restrepo ${ }^{30}$.

La información de la venta de los bienes de la iglesia fue ampliamente difundida por la prensa local, lo que generó una rápida reacción contra la medida del señor Arzobispo, (conservadores como Diego Martínez C. y liberales como Simón Bossa P. se opusieron de inmediato a la decisión de Monseñor Brioschi). El trato se hizo por la suma simbólica de 20.000 dólares, y cuando la venta estaba a punto de llevarse a cabo mediante una escritura pública que se había otorgado en la Notaría Primera, el propio funcionario, Luis Schotbhorg, se encargó de correr la voz por toda la ciudad, "sepan ustedes que el Arzobispo está vendiendo los bienes de la iglesia, y lo que es más grave no a cualquier comprador, sino a un comprador yanqui, ${ }^{31}$. Esta afirmación logró ocupar todos los rincones de la ciudad, de un lado a otro donde se encontraban reunidos uno o más vecinos ó desconocidos; la voz subió de tono y llegó a estremecer de rabia a los ciudadanos. Las

${ }^{27}$ Pedro A. Brioschi, Veinticinco años de episcopado, Cartagena, tip. San Pedro Claver, 1924, pp. 20-21

${ }^{28}$ El 9 de marzo de 1910 se generó una movilización de corte político que tuvo como objetivo principal tumbar la dictadura de Rafael Reyes, el restablecimiento de las libertades civiles y la convocatoria elecciones del congreso. Esta movilización fue una de las primeras en el país en la que el pueblo junto con los dirigentes en oposición al régimen, consiguieron desestabilizar un régimen dictatorial. $\mathrm{M}$. Medina, $\mathrm{La}$ protesta urbana en Colombia en el siglo $X X$.

${ }^{29}$ Durante la hegemonía liberal se buscó disminuir la influencia de la iglesia con medidas institucionales como la desamortización de bienes de manos muertas, la inspección de cultos, el nombramiento de los párrocos y la expulsión de los jesuitas. esto a corto plazo presentó a los liberales como anticlericales, y a los conservadores como los defensores de la iglesia y sus instituciones, como los aliados más convenientes a sus intereses "... los conservadores sirven con lealtad y sano criterio a los asuntos de la iglesia, de la república". Ver Malcolm Deas, "La política en la vida cotidiana republicana" en Beatriz Castro (comp.), Historia de la vida cotidiana en Colombia, Bogotá, grupo ed. Norma, 1996. AHC, "Política conservadora", en Diario de la Costa, Cartagena, diciembre de 1913.

30 AHC, El Porvenir, Cartagena, diciembre 11 de 1910. "Desórdenes en Cartagena", en El Caribe, Cartagena, diciembre 23 de 1910. AEC, “Exposición” en Brioschi, doc. of. № 94, 1910.

${ }^{31}$ Eduardo Lemaitre, Historia general de Cartagena, tomo IV, Bogotá, Banco de la República, 1983. AEC, Pastoral doc. of. № 94, 1910. AHC, "Motines en Cartagena" en El Caribe, Cartagena, diciembre 13 de 1910. "Alocución del gobernador del departamento de Bolívar" y "Cartageneros", en El Caribe, Cartagena, diciembre 22 de 1910. 
cosas tomaron tal rumbo, que el rumor alteró todo el orden, se expandió por contagio y llegó a interesar a todos. "en las calles, plazas, hogares y talleres se elevo al unísono la mas severa protesta". Siendo las cuatro de la tarde un grupo de liberales y conservadores recorrieron las calles de la población. A las siete de la noche la Plaza de la Catedral y las calles adyacentes estaban atestadas de ciudadanos, mientras el señor Arzobispo se refugiaba en la casa del gobernador don José María de la Vega ${ }^{32}$.

Los manifestantes se encaminaron a la casa del gobernador, expresaron ante el mandatario su indignación y la esperanza en que se opusiera a la consumación del hecho; como en esos momentos la banda militar intentó ejecutar su acostumbrada retreta de los sábados en la plaza San Agustín, fueron apedreados. La manifestación se devolvió apenas el gobernador prometió poner fin a la venta. Sin embargo, algunos grupos se dirigieron a la casa del arzobispado y la apedrearon ${ }^{33}$.

El once de Diciembre desde muy temprano carteles desafiantes amanecieron pegados en las paredes invitando al pueblo a que concurriera a una manifestación en el Parque Bolívar a las cuatro de la tarde. Los carteles estaban firmados como "Los directores del mitin". A las tres de la tarde el parque estaba totalmente colmado; cuándo la comisión se dirigía hacia el Parque de Bolívar con el objetivo de llevar a conocimiento del pueblo el pacto que acababa de efectuarse con el gobernador, la policía que rodeaba toda la calle del Arzobispado, sintiéndose intimidada ante la magnitud de los manifestantes abrió fuego contra el pueblo que se defendió con piedras, palos y revólveres, resultando muchos heridos $^{34}$.

Inmediatamente, un considerable número de manifestantes se dirigió a la casa del gobernador exigiendo su presencia en el lugar. El pueblo enardecido pidió entonces la destitución del policía Carlos Díaz (implicado en el tiroteo) y de siete agentes más, además de hacer efectivas sus antiguas peticiones ${ }^{35}$. El gobernador se rehusó ante esta petición y el conflicto se desplazó de un sitio a otro. Ya no solo era contra del Arzobispo sino también contra la autoridad civil, a las que los cabecillas de la protesta dirigían la mirada. Para hacerse fuerte el pueblo fue exhortado a cerrar el mercado público, en algunos de cuyos almacenes existían depósitos de machetes que sirvieron para armarse. Bajo esa amenaza el gobernador accedió a destituir al agente Díaz, y planteó posibles soluciones al conflicto.

\footnotetext{
${ }^{32}$ AHC, "Alocución del gobernador del departamento de Bolívar" y "Cartageneros", en El Caribe, Cartagena, diciembre 22 de 1910.

${ }^{33}$ AEC, Pastoral. doc. of. No 94. 1910. AHC, El Caribe, Cartagena, diciembre 23 de 1910.

34 “En el parque se presentó un piquete del batallón Sucre, la multitud silbó y le arrojó algunos pedruscos, algunos oficiales a cargo del coronel Obando, siguiendo órdenes emprendieron la marcha; la confrontación dejó varios heridos, entre ellos un joven de apellido Lemaitre, quien recibió un balazo estando de pie y mirando como curioso a la multitud. Así mismo otros dos individuos de apellido Sánchez y Sierra resultaron gravemente heridos". AHC, "Sangre", en El Caribe, Cartagena, diciembre 23 de 1910.

35 E. Lemaitre, Historia general de Cartagena; AHC, "Desórdenes en Cartagena" en El Caribe, Cartagena, diciembre 23 de 1910.
} 
El día doce a las cuatro de la tarde fue anulada la escritura, lo que motivó jornadas de furor colectivo. Inmediatamente el Arzobispo prometió viajar al exterior para no volver a ocupar más esta sede. En la noche de ese mismo día la ciudad volvió a su tranquilidad habitual. En la mañana del catorce el Arzobispo cumplió su promesa y partió a bordo del vapor Mercian con destino a Colón ${ }^{36}$. Así finaliza el levantamiento popular contra ese personaje, dejando como saldo varios heridos, un sinnúmero de tiendas saqueadas y un furor colectivo como reacción a la noticia de la anulación de la venta y la retirada de Brioschi de la ciudad $^{37}$.

Este levantamiento popular puso de manifiesto la capacidad de negociación del pueblo con las autoridades eclesiásticas y civiles, y la valoración de su movilización como mecanismo para obtener beneficios o restituir privilegios. La capacidad de negociación que en ese momento tuvo el pueblo se debía a dos factores; uno, de naturaleza coyuntural pero determinante en las negociaciones, la crisis político-ideológica que enfrentó a diversos grupos de la elite cartagenera, con la autoridad eclesiástica; dos, la oposición de la iglesia frente a todo acto de levantamiento popular, caracterizado por tener dentro de sus elementos un componente semipagano, semiindustrial, pluralista y profano, que le permitiría oponerse silenciosamente.

Pedro Adán Brioschi lamentó profundamente la mala interpretación de sus acciones. Durante su exilio escribió varias cartas y pastorales justificando sus razones para la venta. Sin embargo, estos escritos en su mayoría están cargados de su singular sarcasmo, ironía y arrogancia que caracterizaban al prelado. En una de sus pastorales el Arzobispo comenta: "No está demás manifestar que perdono de todo corazón las ofensas irrogadas a mi pobre persona en días aciagos, fruto de una banda de desadaptados que no ven más allá de su ignorancia" ${ }^{, 38}$.

\section{Motivaciones de la protesta de 1910}

La causa principal de la movilización la constituyó la venta de los bienes a extranjeros norteamericanos; en los discursos alusivos a los sucesos se rechaza contundentemente la condición de yanqui del comprador. Al respecto es importante recordar que siete años antes se había producido la pérdida de Panamá a manos de Estados Unidos; la situación de disgusto político aún se mantenía y la venta de estos bienes hizo pensar al pueblo en una nueva intervención americana en propiedades colombianas.

36 AHC, El Porvenir, Cartagena, diciembre 23 de 1910

${ }^{37}$ En El Porvenir, encontramos una carta de algunos integrantes de la colonia siria que fueron blanco de saqueo por parte de la multitud. Afirman que desistieron de sus derechos de demanda ya que consideraban que el acto no era malévolo sino impulsado por la necesidad de sostener aspiraciones del momento. Así mismo saquearon algunas casas como la del convento Santo Domingo de padres eudistas.

${ }^{38}$ AHC, "Carta del arzobispo de Cartagena", en El Provenir, Cartagena, diciembre 13 de 1911. "El asunto Brioschi en las Cámaras”, en El Porvenir, Cartagena, septiembre 6 de 1911. 
Con esta protesta también tambalearon las estructuras del imaginario colectivo implantado por el régimen conservador, dejando ver la vulnerabilidad de la autoridad hasta entonces legitimadora de orden social. La impopularidad de la iglesia en Cartagena y la antipatía hacia los jesuitas, fueron sin duda factores que también influyeron en la opinión pública; gracias a esto se fueron resquebrajando los nexos de poder y autoridad ideológica, entre la iglesia y un sector político social de la ciudad. Algunas poesías de Luís Carlos López traducen una imagen muy generalizada:

¿por qué no he querido ser cura?

Julio Lamba a Carlos Restrepo para que rece por mí.

Lo mismo digo yo sin ironía,

Pues no quise, en mi estólida locura

Ser en mi juventud lo que hoy seria:

ra de pueblo, un bonachón de cura

Vivir en un curato con la pía

Tranquilidad del alma y sin la oscura perspectiva del pan de cada día..

i y todo por llevar una tonsura!

gordo y feliz-y no flaco y maloliente,

masón y radical-con elocuente

y corrugada voz ; que de sermones no hubieran sido los sermones míos,

contra esos mas que bárbaros impíos

llamados liberales y masones!

i con que fogosidad, con que divina

fogosidad hubiese proclamado

la ley secaj... pues ir a una cantina

no es un pecado, ;is no un gran pecado!...

también, viendo una casa clandestina,

muy claramente hubiera condenado

la erótica pasión lucífera

de... los gatos que buscan un tejado... ${ }^{39}$.

De igual forma, la permeabilidad de ideas de corte liberal y socialista y la importancia de la masonería en el conjunto de la sociedad condicionaron un ambiente propicio que permitía la puesta en marcha de opiniones frente a las cuestiones determinantes ${ }^{40}$.

Cuando se identifica a los líderes del movimiento se llega a la conclusión que tenía un claro componente anticlerical, ya que muchos formaban parte de la masonería local. Durante los días del conflicto, y mientras el Arzobispo era expulsado, la élite cartagenera tanto liberales como conservadores- recibía con grandes agasajos la visita del masón,

39 Luís Carlos López, Obra poética, selección de Guillermo Alberto Arévalo, Caracas, Biblioteca Ayacucho, 1994, p. 70.

${ }^{40}$ buena parte de esta nueva postura frente a las cuestiones religiosas entre los artesanos, se debía a la influencia que había tenido en el territorio neogranadino la literatura romántica y utópica de los franceses y la revolución de 1848. esta literatura ofrecía una amalgama de ideas que les permitía ser anticlericales sin ser ateos, y anticatólicos sin ser anticristianos. ver Jaime Jaramillo Uribe, "la influencia de los románticos franceses y de la revolución de 1848 en el pensamiento político colombiano del siglo xix", en La personalidad histórica de Colombia, pp. 164-167. 
general Eusebio Morales ${ }^{41}$. Entre los dirigentes de la protesta había hombres de diferente personalidad y origen social. Se distinguieron los que actuaron desde afuera de la multitud, aquellos que hacían parte de la multitud misma y aquellos que actuaron como intermediarios entre ambos. Se presenta la figura del "comisionado"como representante de la multitud. En su mayoría se encontraban inmersos en el anonimato y llenos de una notada pasión. Estos líderes asumieron el movimiento como un rechazo a la figura del Arzobispo y la posición monopolista de la iglesia católica. Por esta razón, no es difícil encontrar un movimiento en cierta medida coherente cuando alude a unos objetivos claros y guiados por discursos que denotan sus intenciones.

Es más difícil desmembrar la multitud en función de los participantes, líderes y mediadores en el conflicto; esto en gran parte por la inexistencia de fuentes primarias apropiadas al estudio. Pero podemos considerar que en su mayoría estaba formada por el llamado pueblo "raso" Pedro Saltarín (legista), Juana Arteaga (domestica), Filemon Saltarín (sin oficio), Pablo Julio (sirviente), Juan Egea (negociante); panaderos, carpinteros, herreros, mecánicos, latoneros, jornaleros, vendedores al menudeo y ambulantes, carreros, zapateros, sastres, albañiles, textileras, la plebe urbana. Ella mantuvo aspectos primitivos en cuanto que su discurso se mantiene a partir de un modelo moral, y se destaca su actitud por enérgica, patriótica y acertada, es decir, la lucha comunitaria por el bien de todos. La prensa católica de Cartagena mantuvo una visión despectiva hacia la multitud, concebida como una "turbamulta ebria de licor" "holgazanes buenos para nada" y guiada bajo los parámetros inmorales y deformados del socialismo, la masonería y el liberalismo.

La existencia de la acción directa como forma de actuar de la masa es una característica recurrente en este tipo de protesta popular; asonadas caracterizadas por constantes apedreadas contra la fuerza pública; el saqueo de tiendas y de propiedades, robos y el hostigamiento callejero que convulsionaba la rutina diaria, permitiendo que todo el grueso de la sociedad participaran directa e indirectamente en la protesta, por omisión o por voluntad, presionando a la pronta solución del conflicto ${ }^{42}$. Ahora bien, la comprensión del modus operandi del levantamiento popular, es una condición indispensable para su conocimiento. Todo el tejido social se revierte durante la protesta y afloran sentimientos que subyacen en la memoria colectiva de los grupos a favor o en contra de determinada situación $^{43}$. Durante la protesta contra Brioschi se despiertan sentimientos ineludibles que, lesionan y desmembran un cuerpo en viejas y nuevas disputas y rencillas. Antiguas discusiones presentes en el conglomerado de la opinión pública hacen que la élite y el pueblo se sientan en pleno juicio de opinar e interferir en bien de la causa común ${ }^{44}$.

${ }^{41}$ E. Posada, "Iglesia y política en la Costa Atlántica". G. Rudè, La multitud en la historia 1730-1848; E. P. Thompson, Tradición revuelta y conciencia de clase; E. Hobsbawm, Rebeldes primitivos.

42 E. P. Thompson, Costumbres en común.

${ }^{43}$ Mario Aguilera, Insurgencia urbana en Bogotá, Bogotá, Instituto Colombiano de Cultura, 1997; M. Aguilera y R. Vega, Ideal democrático y revuelta popular; Z. Pérez, Revueltas y revoluciones en la edad moderna.

${ }^{44}$ La protesta no buscó un cambio total sino reforzar lo que se consideraba atentaba contra el normal funcionamiento de su cotidianidad. la racionalidad trasciende el mero instinto (en este caso lo que es 
sentimiento patriótico se apoya en un principio de legitimidad cuya base moral es fuertemente aceptada por todos los sectores sociales. Pero en este caso, la legitimidad hace alusión al convencimiento popular de estar defendiendo derechos y costumbre tradicionales apoyados por el amplio consenso de la comunidad ${ }^{45}$.

El movimiento popular, de igual manera, desembocó durante los días posteriores al mismo en actitudes que cuestionaron las políticas centralistas del gobierno nacional, reflejando con ello un elemento de identidad local en oposición al interior del país. La protesta afloró el resentimiento de muchos sectores en contra de la administración del presidente Restrepo a raíz del nombramiento de antioqueños en la aduana en vez de los naturales. Así mismo el levantamiento popular revivió y reforzó antiguas discusiones en torno a una posible descentralización del Estado Colombiano; del apoyo del gobierno hacia los proyectos de la Costa, y de la necesidad, cada vez más apremiante, de impulsar políticas de participación de los "costeños" en los asuntos económicos del gobierno nacional ${ }^{46}$.

\section{Relación, unión y comprensión: el levantamiento popular de 1918}

Los trabajadores portuarios, del ferrocarril y los del río Magdalena, junto con los artesanos de las ciudades de la Costa Atlántica, fueron los primeros en el país en dotarse de organizaciones de defensa y de impulsar luchas de resistencia. Las primeras organizaciones de defensa del trabajador luchaban por asegurar las condiciones mínimas de existencia de la fuerza de trabajo, una mínima estabilidad, el reconocimiento del descanso dominical, la reducción de la jornada de trabajo, la eliminación del trabajo a destajo, el pago en dinero y regular, servicios mínimos de salud, educación, entre otros ${ }^{47}$.

Los conflictos laborales de braceros, tripulantes, cargueros y demás trabajadores portuarios se remontan a finales del siglo XIX pero, solo a principios del siglo XX aparecen registrados. Por ejemplo, en Cartagena en Junio de 1903, se presenta una huelga de panaderos suscitada por la negativa a la disminución del jornal y la exigencia del descanso dominical; en septiembre 13 del mismo año se presenta una huelga de descargadores del muelle, la razón, se exige el aumento del jornal. Estas reclamaciones serán recurrentes en sucesivas movilizaciones en la ciudad: huelga de los carpinteros del muelle, febrero 9 de 1910; braceros del ferrocarril Cartagena-Calamar, febrero 2-17 de

bueno y lo que es malo para impulsar la injusta distribución de un bien común. ver: E. P. Thompson, "la economía moral de la multitud", pp. 217-218.

${ }^{45}$ E. P. Thompson, "la economía moral de la multitud", p. 216.

${ }^{46}$ Los puertos del Caribe colombiano vieron disminuir su participación en la economía nacional a partir del desplazamiento de las rutas comerciales de la costa caribe al pacifico colombiano, originando que la mayoría de los recursos e iniciativas del gobierno hacia la expansión de la economía se enfocara en el pacifico en detrimento de las iniciativas de la costa ocasionado gran malestar e incertidumbre. . ver más información en Eduardo Posada, "Progreso y estancamiento 1850-1930", en A. Meisel, Historia económica y social del Caribe colombiano, pp. 274-275.

${ }^{47}$ Sergio Paolo Solano, Puertos, sociedad y conflictos en el Caribe colombiano, 1850-1930, Bogotá, Observatorio del Caribe Colombiano-Universidad de Cartagena-Ministerio de Cultura, 2003. Alberto Mayor, Cabezas duras dedos inteligentes, Bogotá, Colcultura, 1997. 
1910; trabajadores de la mutualidad, noviembre 3 de 1913; trabajadores de la fabrica de tejidos Merlano, febrero 16 de 1917 entre otros ${ }^{48}$.

En Barranquilla el fenómeno de la huelga hizo su aparición desde muy temprano. Algunos estudiosos del tema coinciden en afirmar que la ciudad asimiló muy tempranamente ideologías progresistas y revolucionarias que circularon por las mismas rutas que traficaba las mercancías, convirtiéndose progresivamente en el centro difusor de formas de resistencia y de ideologías revolucionarias que contribuyeron al mejoramiento de las condiciones de vida de los trabajadores de los puertos y de la naciente industria manufacturera $^{49}$. Por ejemplo, del 25 de abril hasta el 5 de mayo de 1893, se presento la primera huelga de braceros y ferroviarios, en esa ciudad y en la recién fundada población de Puerto Colombia. La protesta obedeció a la negativa de los trabajadores del ferrocarril y de los vapores fluviales a laborar por menos de $\$ 10$ reales. La petición inicialmente estuvo dirigida a las empresas navieras y a la Aduana, entidad gubernamental, y luego se extendió al resto de las empresas, industrias y talleres.

Este movimiento logró paralizar la actividad comercial por espacio de 10 días, y se extendió a otras espacios de la actividad económica: "Veranillo, empresa algodonera; La Esmeralda, fábrica de licores; La Acoholina, fábrica de licores; La Cubana, fábrica de jabón, las fábricas de hielo y azúcar del señor Pochet; la empresa nacional de canalización; el acueducto", entre otros. ${ }^{50}$ Las acciones emprendidas por la multitud sumieron a la cuidad en un completo caos, un periódico de la cuidad describe lo sucedido: "el servicio de electricidad ha sido cortado, la ciudad permanece a oscuras, se suspendió el servicio de agua potable., las vías del ferrocarril fueron blanco de los huelguistas, por tanto no hay trasporte de un lado a otro de la cuidad, la desesperación es presa de todos",51.

Las condiciones socio-económicas en las que se desarrolló la huelga, permitieron que el conflicto se resolviera oportunamente. La política monetaria de los gobiernos regeneradores había desatado una crisis económica la que al tiempo que favorecía a los sectores empresariales vinculados al comercio internacional generó una crisis fiscal y un alto índice de inflación que se reflejó en el encarecimiento del costo de vida, el

\footnotetext{
${ }^{48}$ Para algunos historiadores, durante los años veinte ocurrió una oleada de huelgas que marco el inicio de la protesta organizada de la clase obrera en Colombia. las huelgas comenzaron en 1919, año en el se declararon 15 conflictos laborales. Pararon los empleados de los ferrocarriles, los portuarios y en Bogotá, los albañiles y los conductores de tranvías, quienes exigieron la jornada laboral de nueve horas y aumentos de salario. no obstante hoy se conoce de conatos de huelga desde 1893 y1918 de gran significación histórica. Ver E. Caicedo, Historia de las luchas sindicales en Colombia; Daniel Pècaut, Política y sindicalismo en Colombia, Bogotá, ed. La Carreta, 1973; Mauricio Archila, Cultura e identidad obrera. Colombia 1910-1945, Bogotá, Cinep, 1991; M. Urrutia, Historia del sindicalismo en Colombia; Charles Bergquist, "La historia laboral latinoamericana desde una perspectiva comparativa", en Estudios Sociales No 5, Medellín, Faes, 1989, pp. 13-26.

49 En Barranquilla nació la Fedenal (Federación Nacional de Trabajadores del Trasporte). Ver más información en: Mauricio Archila, Barranquilla y el rio una historia social de sus trabajadores, Bogotá, Cinep, 1987.

${ }^{50}$ Biblioteca Nacional de Colombia [BNC], Diario de la tarde, Barranquilla, abril 28 de 1893.

${ }^{51}$ BNC, El Anotador, Barranquilla, mayo 2 de 1893.
} 
estancamiento de los salarios y su perdida de poder adquisitivo. Entonces, al tiempo que las posibilidades de trabajo crecían en los puertos, el jornal devengado y el costo de vida generaban insatisfacciones entre los obreros ${ }^{52}$.

El primero de enero de 1918 nuevamente Barranquilla fue escenario de un paro general de trabajadores, el que se prolongó durante varios días, hasta que el cuatro de ese mes las autoridades, empresarios y trabajadores acordaron un aumento salarial. El aumento de los jornales en Barranquilla fue incentivo para protestas obreras parecidas en otras ciudades de la región, como fue el caso de Cartagena y Santa Marta. El 7 de enero de 1918, la actividad portuaria y empresarial de Cartagena se vio forzada a suspender sus actividades diarias, como consecuencia de una huelga de carreteros y trabajadores del puerto, organizada por la sociedad de Artesanos y Obreros de la ciudad, en la que participaron más de mil obreros.

Del el 7 al 9 de enero de 1918 los braceros que movilizaban la carga en el ferrocarril (Cartagena-Calamar), junto con los carreteros y cargueros del muelle La Bodeguita, dejaron de laborar tres días exigiendo aumentos en el jornal y reducción de la jornada laboral de nueve a ocho horas diarias, petición inicialmente dirigida a la compañía United Fruit Company y luego extendida al resto de las empresas navieras e industrias de la ciudad. Para evitar la parálisis del puerto, los empresarios trajeron varios empleados de Turbaco para suplir las necesidades de carga y descarga; la iniciativa convulsionó, aún más los ánimos de los trabajadores, quienes argumentaban ser los únicos que podían suplir esas necesidades" ${ }^{25}$. Los trabajadores venían expresando su descontento por el jornal que recibían de las empresas (70 centavos), argumentando que las excesivas rentas fiscales, habían aumentado el costo de vida, los víveres, bebidas y demás artículos de primera necesidad, y en consecuencia sus ingresos debían aumentar. Las extensas jornadas de trabajo (de 6:00 a.m. a 6:00 p.m. y turnos extras; desde 6:00 p.m. a 12:00 p.m. y de 12:00 a.m. a 6:00 a.m.), de igual manera debían ser organizadas a horarios más cómodos o apropiados bajo un jornal justo.

Por otro lado, la huelga de braceros en Sincerín, paralizó la producción de los ingenios azucareros, lo que originó un alza en el precio de la caña de azúcar y con ello en el azúcar de consumo doméstico. El arroz, otro producto de consumo básico, también subió de peso, siete centavos la libra, originando gran malestar entre las amas de casas ${ }^{54}$.

El día siete a las ocho y treinta de la mañana se presentaron varios carreros en la Plaza de la Aduana y con voces alarmantes invitaron a los colegas que estaban allí esperando trabajo, a que desengancharan los carros y se marcharan para sus casas. “¡Huelga! ¡Huelga!, gritaban, no trabajamos sino se nos pagan los viajes más caros que de costumbre" ${ }^{\text {. }}$. En la bodega

\footnotetext{
${ }^{52}$ S. Solano, Puertos, sociedad y conflictos en el Caribe colombiano; M. Archila, Barranquilla y el río.

53 AHC, "La huelga de descargadores", en La Época, Cartagena, enero 10 de 1918; "La huelga de trabajadores" y "Protesta de obreros en La Machina", en El Porvenir, Cartagena, enero 10 y 12 de 1918.

${ }^{54}$ AHC, "Por qué está caro el arroz", en La Época, Cartagena, enero 15 de 1918

${ }^{55}$ AHC, "Huelga en Cartagena", en La Época, Cartagena. enero 10 de 1918. "Más detalles de la huelga", en El Porvenir, enero 14 de 1918.
} 
del ferrocarril los carreros junto con los cargadores se oponían al descargue de víveres procedentes de las poblaciones cercanas, y los que estaban descargados no tenían quienes las trasportaron: "hoy no se mueve ni una paja", era la voz genera $1^{56}$. Mientras esto sucedía en la Bodeguita, en la Boca del Puente se había congregado una multitud de unas trescientas a cuatrocientas personas. Se movilizaron a la fábrica de hilados de los señores Justo de la Espriella y Co, la fábrica Walters, la Empresa de Molinos de Trigo de propiedad de Manuel Angulo, a los Talleres de Tejido del Banco Unión y finalmente al Taller Americano, cruzando unos por el Puente del Espinal y otros por el Paseo Heredia. La voz general era: “iparen las máquinas y todo el mundo a la calle!” En estos establecimientos solicitaron a los obreros que allí laboraban se les unieran a la huelga, obligando a los empresarios a cerrar sus negocios en prevención a ataques contra la propiedad ${ }^{57}$. Aquellos que al paso de multitud se rehusaban a participar en la huelga eran seriamente reprendidos, como fue el caso del humilde carretillero David de La Hoz, quien fue víctima de los huelguistas, "el carro fue desenganchado, la mula colocada a un lado y los productos desparramado... está ahora a nuestra disposición" ${ }^{, 58}$.

A las once de la mañana, los huelguistas en número de dos mil se encontraban en Manga; allí lograron suspender los trabajos de las fábricas de Jabones La Palma, Villareal, Sombreros y Perfumes Lemaitre y la de hielo de los señores Franco y Co., habiendo antes suspendido los trabajos de ladrillería y alfarería. Una hora después todas las fábricas de la ciudad estaban paradas, inclusive las imprentas. Todas las cantinas, bares, y demás lugares de expendios de bebidas alcohólicas fueron cerrados. Los rumores iban y venían de un rincón a otro de la ciudad, interesando e involucrando a todos, impartiendo un ritmo propio a los levantamientos. Un periódico de la época describe el desarrollo de la jornada: "Solo se escucharon comentarios de que [al] día siguiente no habrá mercado ni cocineras, porque éstas querían también aumento... Así como los jornaleros exigían debía arreglarse de una vez la rebaja del precio de los víveres, so pena de que al día siguiente no hubiera comida para nadie., estancia ni alacena barata"59.

\section{Diálogo y mediación}

Para evitar la parálisis del puerto, y por consiguiente de la ciudad, las autoridades civiles, en cabeza del señor gobernador Dr. Enrique J. Arrázola, junto con el general Lácides Segovia, en reunión unánime con los industriales y los obreros, iniciaron diálogos sobre las posibles soluciones al conflicto. Los señores Mr. Tyleer superintendente del ferrocarril, Diego Martínez Camargo (representante de la Cartagena Oil Refining Co.), Justo de la Espriella, Eduardo Martínez y José Manuel de Aparicio, fueron los representantes de los empresarios. En representación de los obreros, José Gil Lorduy, Rodrigo Ortiz y Gómez,

\footnotetext{
${ }^{56}$ AHC, El Porvenir, Cartagena, enero 14 de 1918.

57 AHC, Diario de la Costa, Cartagena, enero 12 de 1918; "La autoridad y el mitin", en Gaceta Departamental de Bolivar, Cartagena enero 9 de 1918.

${ }^{58}$ AHC, "La autoridad y el mitin”, en Gaceta Departamental de Bolivar, Cartagena enero 9 de 1918.

${ }^{59}$ AHC, “La autoridad y el mitin”, en Gaceta Departamental de Bolívar, Cartagena enero 9 de 1918.
} 
Eustorgio Mouthon Vélez, Pedro Periñán, Carlos Escallón, y otros miembros de la Sociedad de Artesanos y Obreros de Cartagena ${ }^{60}$. Después de amplias deliberaciones se llegó al siguiente acuerdo: reducción de la jornada laboral de nueve a ocho horas, y aumento del $50 \%$ para los salarios de $\$ 1,50$ para abajo; $40 \%$ para los de $\$ 1,70 ; 30 \%$ para los de $\$ 1,90,25 \%$ para los de $\$ 2,00$ para abajo. La multitud que esperaba ansiosa en la calle recibió con gran expectativa el pacto señalado, retirándose a sus hogares ${ }^{61}$.

El día nueve ocurrieron dos incidentes que de nuevo incitaron a la protesta. El primero se debió a que el silbato del taller Americano de propiedad del ferrocarril volvió a pitar llamando a las seis de la mañana, cuando se suponía debía hacerlo a las siete, dado que la jornada había sido reducida una hora. El segundo se debió a la negativa de muchos jefes de taller o capataces a cumplir lo pactado (el aumento del salario y la disminución de las horas de trabajo). Ambos incidentes ocasionaron que la huelga se reanudara.

El motín aumentaba, la intranquilidad y la alarma se tomaba la ciudad; el pueblo se dirigió a las tiendas del mercado [carnicerías, pulperías, bodegas y demás almacenes comerciales], y rompiendo las puertas se armó de machetes, rulas y revólveres, "las cocineras regresaban del mercado espantadas con sus cestas vacías porque no había manera de comprar nada; las oficinas del comercio comenzaron a cerrar el ferrocarril se disponía a partir y la multitud desenganchó algunos rieles",62.

Los ánimos estaban convulsionados, la multitud estaba cansada de disculpas y falsas promesas; los ídolos del día anterior eran fuertemente ignorados y abucheados (como Carlos Escallón). Al llegar frente a los talleres de los señores Franco y Co., Diego Martínez y Co. y Pombo Hermanos, reanudaron la acción emprendida en el mercado de abrir violentamente las puertas. La destrucción de la propiedad, junto con los saqueos, muestra un grado más de la reacción popular durante la protesta, que va desde un mero reflejo de defensa, la voluntad de represión o el deseo de intimidar para lograr sus objetivos. El pueblo en revuelta destruye los símbolos de la opresión y de la miseria; esto tiene un contenido de clase y una finalidad política, representa el arma del pueblo contra la elite.

La policía rodeó la ciudad. Una parte en la Plaza de la Aduana, otra en la Plaza de Bolívar, y otra en la Plaza de los Coches, puntos clave para contener la protesta. Se ordenó el respeto hacia la propiedad privada, y se les intimidó con bayonetas, pero el pueblo ignoró las advertencias de la policía continuando con sus acciones; comenzó así un cruce de disparos en varios puntos donde se concentraba la multitud [en el Portal de los Dulces, la Boca del Puente y parte del Camellón], resultando en estos enfrentamientos cuatro muertos, tres particulares y un agente de policía y varios heridos. La prensa local describe

${ }^{60}$ Carmen Escobar, La revolución liberal y la protesta del artesanado, Bogotá, ed. Fondo Suramericano, 1990. AHC, "La sociedad de artesanos", en Diario de la Costa, Cartagena, enero 12 de 1918.

${ }^{61}$ E. Lemaitre, Historia general de Cartagena, tomo IV, p. 536. AHC, Diario de la Costa, Cartagena, enero 14 de 1918. Gaceta Departamental de Bolívar, Cartagena, enero 14 de 1918. AHC, El Porvenir, Cartagena, enero 12 de 1918; AHC, La Época, Cartagena, enero 10 de 1918.

${ }^{62}$ AHC, "Huelga en Cartagena", en La Época, Cartagena, enero 10 de 1918. 
así:" El señor Andrés Lozana ha sido herido como consecuencia de un disparo en el pulmón, de oficio carpintero, se encontraba situado en los bajos del puente cuando una de las balas lo encontró. Dos señores de apellido Jiménez fueron heridos en el Camellón (en la esquina del mercado). Fallecieron el agente Domingo Guzmán y el señor Alejandro Labiosa" ${ }^{, 63}$.

El desarrollo de las acciones fue descrito por la prensa nacional: "La consternación subió a su período álgido, la sangre manchaba los andenes de las calle, los amotinados corrían desesperadamente de un lado a otro [buscando] refugio, llevando los machetes unos, otros votándolos. Las puertas se cerraban estrepitosamente y los llantos de las madres y esposas contristaron los ánimos, se hizo el tradicional cierre depuestas", todavía vigente para la época $^{64}$.

A través de carteles ubicados a lo largo de la ciudad, el gobernador reiteraba una vez más el pacto firmado el día anterior. El señor alcalde, de igual manera, consideró que el acuerdo debía hacerse efectivo y de cumplimiento por ambas partes. La opinión pública quedo profundamente sorprendida por la magnitud y las características de la huelga. Aún los editorialistas de izquierda de la prensa liberal condenaron el ataque a la propiedad. Por lo tanto, cuando el gobierno declaró la paz turbada en la Costa Caribe la prensa de todos los matices políticos aplaudió la medida que sentó tan peligroso precedente. Al declarar el Estado de Sitio el gobierno quedó en capacidad de prohibir las reuniones de cualquier comité de huelga permanente. El decreto 2 de 1918, estableció que ningún trabajador podía ser representado por una no persona que perteneciera a su gremio o que no perteneciera a la misma empresa, y quienes no cumplían esto eran encarcelados, lo cual de hecho prohibía los comités de huelga permanente, las manifestaciones y los piquetes de huelga ${ }^{65}$.

El señor gobernador convocó a un grupo de civiles entre ellos a don Jerónimo Martínez y don Diego Martínez, para el control y vigilancia de las plazas y alrededores de la ciudad; junto con la recolección de machetes en La Quinta y en Alcibia, puntos según se conoce de mayor concentración de las armas. La guardia civil se aseguró de detener a más de cien personas implicadas en el conflicto. Entre ellos destacamos a Miguel Arco, Catalina Morales, Luis Aguilar, Emilio Aguilar, Alejandro Castro, Pedro Gómez, Víctor Vargas, Mauricio Jiménez, Gilberto Meléndez, Néstor Ramírez, Heliodoro Maza, Sebastián Maza, Pedro Correa, Francisco Núñez, Bernardo Prado, Manuel de Ávila, Enrique Guillén, entre otros $^{66}$.

${ }^{63}$ AHC, Diario de la Costa, Cartagena, enero 11 de 1918

${ }^{64}$ AHC, La Época, Cartagena, enero 12 de 1918; "La huelga en línea" y "Más detalles de la huelga", en El Porvenir, Cartagena, enero 14 de 1918.

65 AHC, "Texto del pacto celebrado entre los industriales y los obreros ante el gobernador del departamento", en El Porvenir, Cartagena, enero 11 de 1918; "El presidente de la república declara turbado el orden público en toda la Costa Atlántica", en El Porvenir, Cartagena, enero 12 de 1918.

${ }^{66}$ AHC, La Época, Cartagena, enero 13 de 1918; "Contra la huelga", en Diario de la Costa, Cartagena, enero 12 de 1918. 
Los trabajadores e industriales se reunieron el día ocho en el salón Amarillo ubicado en el edificio de la gobernación y luego de una larga deliberación finalmente se llegó a un acuerdo: salarios de $\$ 1,50$ para abajo aumento del $50 \%$; hasta $\$ 1,70$ aumento del $40 \%$; hasta $\$ 1,90$ aumento del $30 \%$, y de $\$ 2$, oo para arriba del $25 \%$. Para los cargadores $\$ 1$, oo por día desde las seis de la mañana hasta las doce del medio día, $\$ 0,18$ la hora, y desde las doce hasta las seis de la tarde, $\$ 0,24$ la hora. Ocho horas diarias de trabajo, los individuos que trabajen por tareas quedan comprendidos en el $50 \%$ que se ha hablado ${ }^{67}$.

Todas las fábricas de la ciudad, incluido el taller del ferrocarril, a las siete de la mañana del día 9 tenían laborando a todos los obreros y el ritmo diario poco a poco retornaba a la normalidad, el comercio abrió parcialmente sus tiendas, el mercado reanudó sus funciones, y solo quedaban unos pocos despreocupados de las labores diarias.

Las negociaciones prometieron soluciones viables a todos los implicados en el conflicto. Los trabajadores portuarios, de quienes dependía el buen funcionamiento del comercio y por lo tanto la vida económica de extensas zonas, adquirieron a raíz de los hechos suscitados un singular poder de negociación frente a los patronos y al gobierno. El mundo económico en que estos se movían les permitió sincronizar sus propuestas con los ciclos de la economía internacional y nacional, con la oferta laboral, con el movimiento de carga y con las ganancias de la empresa que estaban a la vista, por la intensidad del movimiento de trenes, vapores, el volumen de la carga y los precios internacionales. Por eso desarrollaron una gran capacidad para desafiar a los empresarios ${ }^{68}$.

La capacidad de negociación que en se momento tenían los trabajadores obedeció a que iniciaron el cese de actividades en un momento de congestión de carga en el puerto, por lo que hacía vulnerable a los empresarios muy necesitados del despacho rápido de las mercancías, estrategia de la que los trabajadores siempre sacaron partido para fortalecer su capacidad de negociación frente a aquellos y el Estado. Así mismo, la ausencia de una oferta de mano de obra ilimitada que permitiera reemplazar a los trabajadores que se encontraban en huelga, hizo más eficaz la protesta. Por último la crisis política nacional, que enfrentaría al interior del país con la Costa Atlántica; asimilando dentro del juego de relaciones y poderes, a los sectores populares ${ }^{69}$.

\section{Conclusiones}

La historia desde abajo otorgó al grueso de la sociedad, hasta cierto punto por encima de las distinciones sociales, una identidad heredada de sus propios esfuerzos. Atrás ha quedado la multitud desdibujada e invisible en los acontecimientos históricos, al ser susceptible de definición. Esta investigación renunció a sus intenciones iniciales de

\footnotetext{
${ }^{67}$ AHC, "Contra la huelga", en Diario de la Costa, Cartagena, enero 12 de 1918.

${ }^{68}$ S. Solano, Puerto, sociedad y conflicto en el Caribe colombiano 1850-1930; AHC, Diario de la Costa, Cartagena, enero 12 de 1918.

${ }^{69}$ Sergio Paolo Solano, Trabajo libre, concertaje forzoso y sectores subalternos en la región Caribe colombiana en el siglo XIX. Mecanografiado.
} 
desmembrar la multitud a favor de los representantes en las movilizaciones de protestas. Colocando los esfuerzos en el estudio de dos movimientos populares dados en Cartagena entre el año de 1910 y 1918.

Durante la Regeneración las libertades individuales se vieron seriamente restringidas por la imposición de una normatividad religiosa que imponía el Estado. El imaginario colectivo se veía así, sumergido en un sin numero de obligaciones, y actitudes que reforzaran el ideal moral-cristiano (el control sobre la prensa, las movilizaciones populares, y los espacios de sociabilidad laboral y domestica, fueron una necesidad temprana del clero, que permitió la viabilidad de sus disposiciones). Sin embargo, en Cartagena, como en el resto de la Costa Caribe, la débil influencia de la iglesia se hacía cada vez mas notoria a través del predominio de las uniones ilegitimas, hijos naturales, presencia de grupos de protestantes y de ideologías socialistas, comunistas, y la influencia de la masonería, lo que originó que las movilizaciones tomaran matices diferentes al resto del país.

El levantamiento popular suscitado los días 10, 11,12 de diciembre de 1910 en la ciudad se presentó como un motín antiimperialista, y luego bajo un sentimiento regionalista que colocaba viejas discusiones, y resentimientos al orden del día. La multitud logró disolver la venta de los bienes de la iglesia, amparados en una base moral, por la cual creía defender los intereses generales de posibles extranjeros. Esta actitud era estimulada por la intervención, no hace más de siete años de los Estados Unidos en Panamá. Al término del levantamiento la ciudad retorno a su calma habitual sin embargo, en el ámbito ideológico, se cernían nuevas inquietudes respecto al papel de la multitud y la efectividad de sus movilizaciones.

Solo con la huelga de braceros de Cartagena en 1918, se valora la trascendencia de las movilizaciones de los sectores populares de la ciudad y en la Costa Caribe. Desde 1893, 1910 a 1918 las huelgas en los puertos de esta región, trascienden los marcos morales hacia realidades más cercanas a las necesidades de los trabajadores, expresadas en el aumento del jornal, reducción de las horas de trabajo, entre otras peticiones que permitirían algún mejoramiento en las condiciones materiales de vida.

Las ideologías foráneas, si bien, son esenciales en la formación ideológico-política del trabajador, poco influyeron, como los procesos de asimilación y apropiación de identidades laborales develadas de los procesos, económicos, políticos, sociales y culturales que vivió la costa Caribe. La creación de la Liga Costeña en 1919 se constituía en el sentimiento de identidad regional, permeado desde las capas superiores a las capas inferiores, oposición al interior del país. En oposición al progresivo desplazamiento de las rutas de la Costa Caribe al Pacifico Colombiano. 